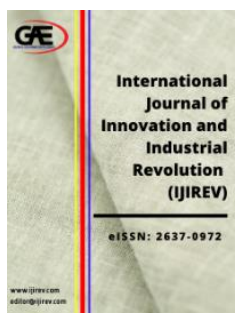

\author{
INTERNATIONAL JOURNAL OF \\ INNOVATION AND \\ INDUSTRIAL REVOLUTION \\ (IJIREV) \\ WWW.ijirev.com
}

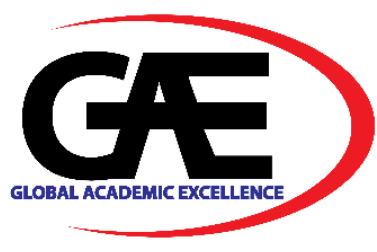

\title{
THE DEVELOPMENT OF ARDUINO BASED EDUCATIONAL KIT: TRAFFIC LIGHT PROTOTYPE TO INCREASE THE USER BASIC KNOWLEDGE ON WRITING SIMPLE ARDUINO PROGRAMMING CODE
}

\author{
Syarfadila Ezurida Shaari ${ }^{1}$, Farihana A. Rahman ${ }^{2}$, Che Susilawati Che Berahim ${ }^{3}$ \\ 1 Department of Mechanical Engineering, Politeknik Mukah, Malaysia \\ Email: fadila.shaari@pmu.edu.my \\ 2 Department of Mechanical Engineering, Politeknik Mukah, Malaysia \\ Email: farihana@pmu.edu.my \\ 3 Department of Mechanical Engineering, Politeknik Mukah, Malaysia \\ Email: che_susilawati@pmu.edu.my \\ Corresponding Author
}

\section{Article Info:}

Article history:

Received date: 28.02 .2021

Revised date: 20.03 .2021

Accepted date: 29.03.2021

Published date: 31.03 .2021

\section{To cite this document:}

Shaari, S. E., Rahman, F. A., \& Che Berahim, C. S. (2021). The Development of Arduino Based Educational Kit: Traffic Light Prototype to Increase The User Basic Knowledge on Writing Simple Arduino Programming Code. International Journal of Innovation and Industrial Revolution, 3 (6), 27 35.

DOI: $10.35631 /$ IJIREV.36003

This work is licensed under CC BY 4.0 (c) $(2$

\begin{abstract}
:
This paper presents a simple Educational Kit based on the UNO Arduino platform. This prototype is intended for the Mechanical Engineering Department of Politeknik Mukah's students. Its main aim is by using the developed prototype, the students' basic knowledge on writing a simple Arduino program code will increase thus helping the students to fulfill their final year project theme. Along with the prototype, a ready written code will be provided, however, the students will be required to manipulate the said coding in setting the LED traffic light based on the given sequence. After using the suggested prototype, the percentage of students who were having difficulties in writing the Arduino program code student decreased by $65 \%$.
\end{abstract}

Keywords:

Arduino, Education, Programming, Technology, IR4.0 


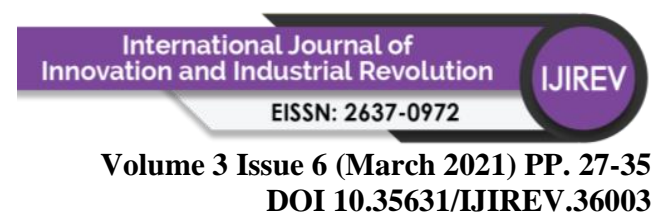

\section{Introduction}

The Fourth Industrial Revolution also called IR4.0 referred to the latest phase in the Industrial Revolution (Schwab, 2016). With this strategic initiative announcement made by the German government of this new phase, industries worldwide began to focus on automation, machine learning, real-time data, and interconnectivity (Rojko, 2017). According to the report on Readiness for the Future of Production Report 2018, published by World Economic Forum (WEF) and A.T. Kearney, which has assessed 100 countries, Malaysia is in the "Leader" quadrant position, thus naming Malaysia as one of the countries that have a strong current manufacturing position which stating Malaysia's readiness in facing the IR 4.0 (MITI, 2018). Therefore, Polytechnic too has begun preparing the students for this challenge.

Based on a survey distributed amongst a group of students, it was found that most of the respondents did not understand and were not able to list down all the key components of IR4.0 concepts. Therefore, to prepare the students, one of the efforts made by Polytechnic's lecturer was to set up an IR4.0 theme for the student's final year project (FYP). One of the cheapest and easiest tools to apply IR4.0 is by using the Arduino platform. However, the syllabus for Mechanical Engineering's program did not cover the learning for Arduino program writing. The lecturers and students had to find an alternative to ensure that they are prepared in facing this phase. And due to the nature of the learning environment provided by the Polytechnic, a practical exercise and demonstrations by using a prototype are the best approach to assist the student in applying IR 4.0 concept. Arduino-based traffic light prototype is a project that helps the students to understand how to write and manipulate simple programming code for a traffic light-based prototype using an Arduino and how it operates. Hence, this project will help the students to gain basic knowledge using Arduino as we reach in IR4.0 by programming a traffic light prototype as learning equipment. This project aims to develop a prototype to assist the Politeknik Mukah's Mechanical Engineering's final year students in writing the UNO Arduino's basic coding.

\section{Literature Review}

\section{Arduino}

Arduino is an easily programmed, erased ad reprogrammed open-source microcontroller. The Arduino platform was introduced in 2005 which offers an inexpensive and easy way to assist inexperienced users to control sensors and actuators by constructing and programming electronic devices. Table 1 (Arduino, 2011) below has listed a few differences between the top three (3) most commonly used Arduino boards in the market (Loius, 2016).

Table 1: Arduino UNO vs Leonardo vs Mega 2560

\begin{tabular}{|l|c|c|c|}
\hline \multicolumn{1}{|c|}{ Type } & UNO R3 & Leonardo & Mega 2560 \\
\hline Boards & ATmega328 & ATmega32u4 & ATmega2560 \\
\hline Digital I/O & 20 & 23 & 54 \\
\hline Analogue Inputs & 6 & 7 & 16 \\
\hline PMW & 6 & 6 & 15 \\
\hline Program Interface & USB via Atmega16U2 & USB via Atmega32U4 & USB via Atmega16U2 \\
\hline
\end{tabular}


Volume 3 Issue 6 (March 2021) PP. 27-35 DOI 10.35631/IJIREV.36003

\section{Arduino Language}

Utilizing a software called Integrated Development Environment, IDE, Arduino boards can easily be programmed. According to Hernando Barragán, the creator of the language, Arduino language is the language abstracted and simple for artists, designers as well as engineers to understand and use. Having some similarity with the $\mathrm{C}++$ language, Arduino language is said to use C++ as its library (Barragán, 2004).

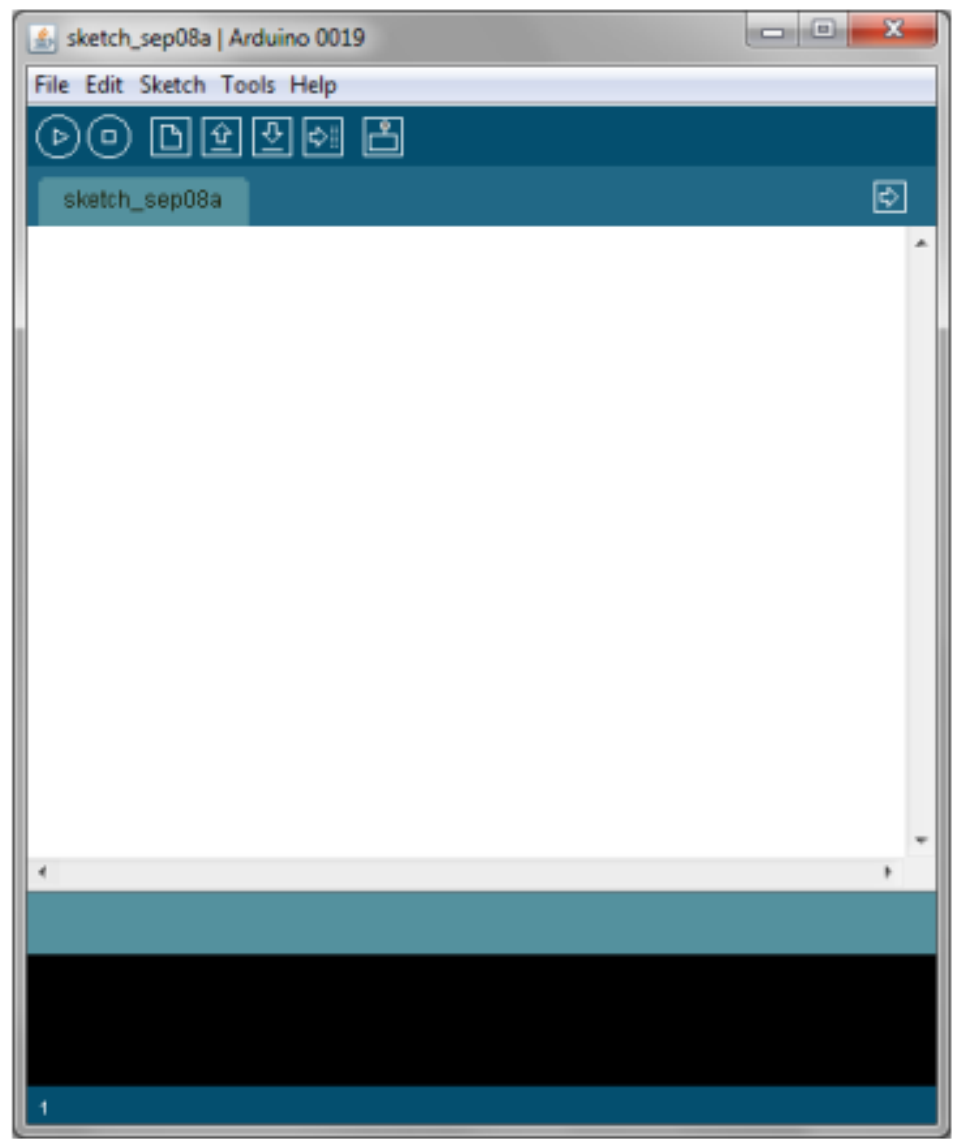

Figure 1: Arduino IDE main Window

Source: Arduino Cookbook by Michael Margolis. Copyrighted 2011 by O'Reilly Media Inc.

Arduino programming languages are made up of three main parts. The first one is functions that allow the user to control the board by analyzing characters, perform mathematical operations, and various tasks. For example:

a) digitalRead () - read a value to a certain pin

b) digitalWrite () - write a value to a certain pin

c) setUp() - executes once the board is powered up or reset

d) $\operatorname{loop}()-\operatorname{loop}$ the program repeatedly until the board is powered off or reset

The next part of Arduino programming language is value which represents constants and variables that is similar to $\mathrm{C}++$ data types such as array, bool, char, float, etc. Last but not least, the last part of Arduino programming language is called structure, which often contains small code elements such as operators (Margolis, 2011). 


\section{Methodology}

\section{Project Planning}

This project started by identifying the problems faced by the surrounding users. A controlled group of 40 students who took up the DJJ6143 Project 2 was asked to answer a few short questions on the IR 4.0 concept and Arduino. Based on the obtained result, the flow chart for the whole project planning was constructed as shown in Figure 2 (Karl T. Ulrich, 2008) below. To counter the said problem, few ideas have been laid out and chosen.

Product specifications then were listed out making sure the product would not stray from the main purpose. Multiple concept generations were suggested about the previously established elements needed to tackle the lack of basic knowledge for the students in Arduino program code writing.

A few concepts were generated by brainstorming components as shown in Table 1 (Cross, 2008) and the shortlisted concepts were evaluated by using the Pugh method. Based on Table 2 (Pugh, 1981), Concept 1 was chosen since the components listed in concept 1 are easy to use, power-saving, and durable compared to the other two concepts suggested.

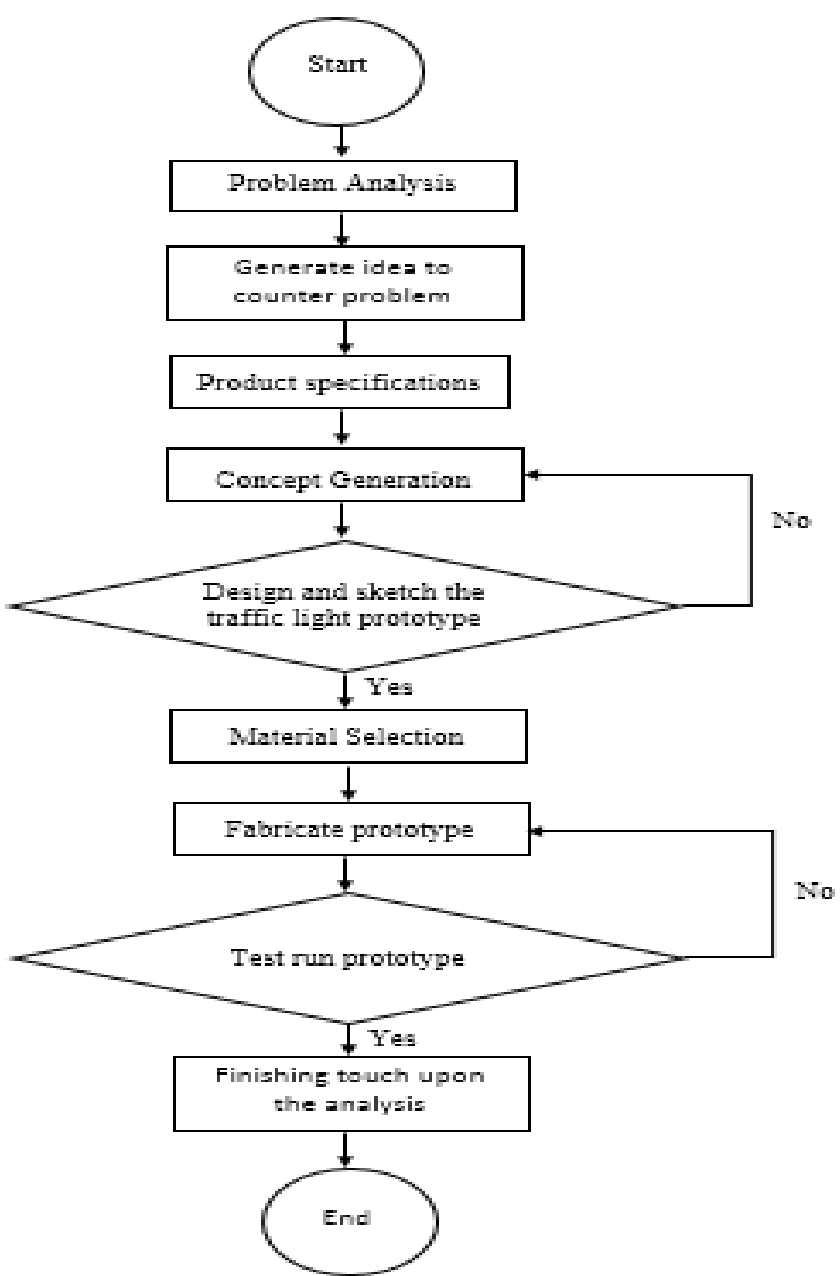

Figure 2: Project Planning Flowchart

Source: Product Design and Development, $4^{\text {th }}$ Edition by Karl T. Ulrich. Copyright 2008 by McGraw-Hill Companies, Inc. Adapted. 
Volume 3 Issue 6 (March 2021) PP. 27-35

DOI 10.35631/IJIREV.36003

Table 1: Concept Generation Based on Morphology Chart

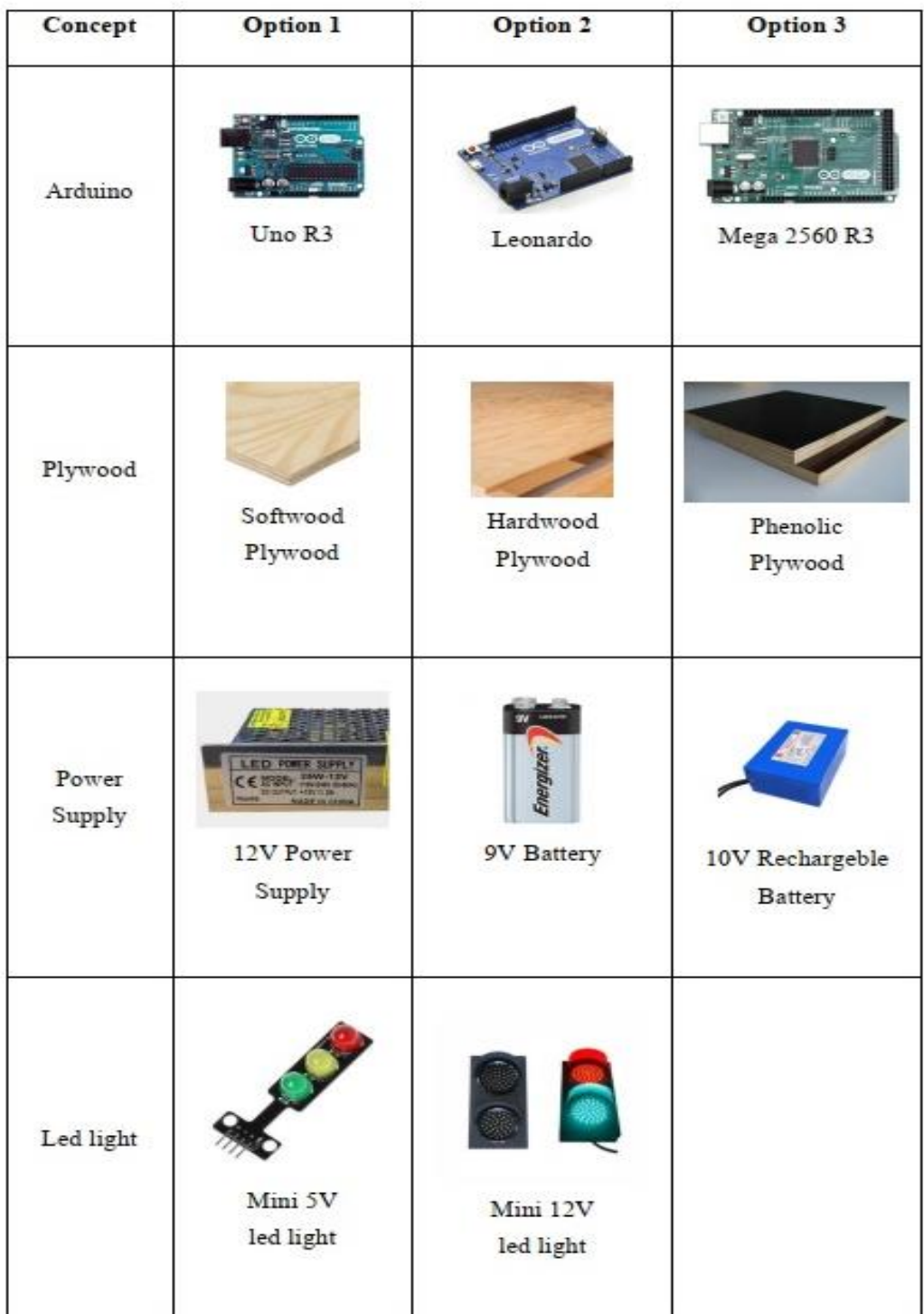

Source: Engineering Design Methods: Strategies for Product Design 4th Edition by Nigel Cross. Copyright 2008 by Wiley. Adapted.

Table 2: Decision Matrix using Pugh Chart

\begin{tabular}{|c|c|c|c|}
\hline & Concept 1 & Concept 2 & Concept 3 \\
\hline Cost & + & + & + \\
\hline Easy to use & + & - & - \\
\hline Power saving & + & + & - \\
\hline Durable & + & + & + \\
\hline Total (+) & 4 & 3 & 2 \\
\hline Total (-) & 0 & 1 & 2 \\
\hline Overall & 4 & 2 & 0 \\
\hline
\end{tabular}

Source: Concept Selection: A Method That Works by Stuart Pugh. Copyright 1981 by Heurista. Adapted

\section{Arduino Educational Kit}

After much considerations, the final design of the prototype was sketched up and drawn using Autodesk Inventor software with the dimension of $1.5 \mathrm{~m}(\mathrm{~L}) \times 0.42 \mathrm{~m}(\mathrm{~W}) \times 0.07 \mathrm{~m}$ Copyright (C) GLOBAL ACADEMIC EXCELLENCE (M) SDN BHD - All rights reserved 


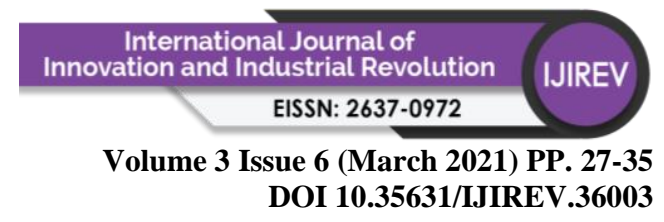

(H) as shown in Figure 3 below. By using the selected concept and the suggested design, the prototype was then fabricated. Figure 4 and Figure 5 shown are the finished product of this Arduino Based Educational Kit: Traffic Light Prototype and the schematic diagram for its main circuit using Arduino UNO itself.

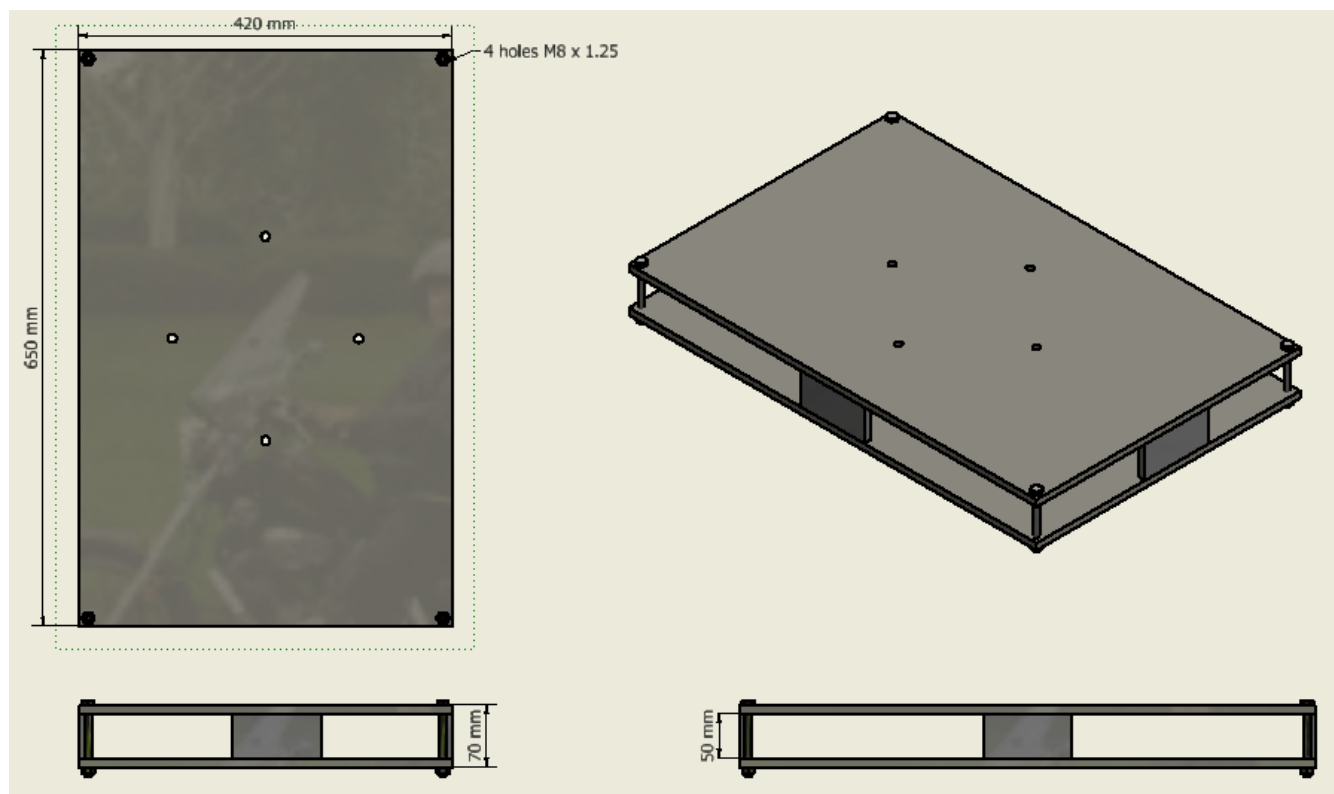

Figure 3: Detailed Design of the Prototype

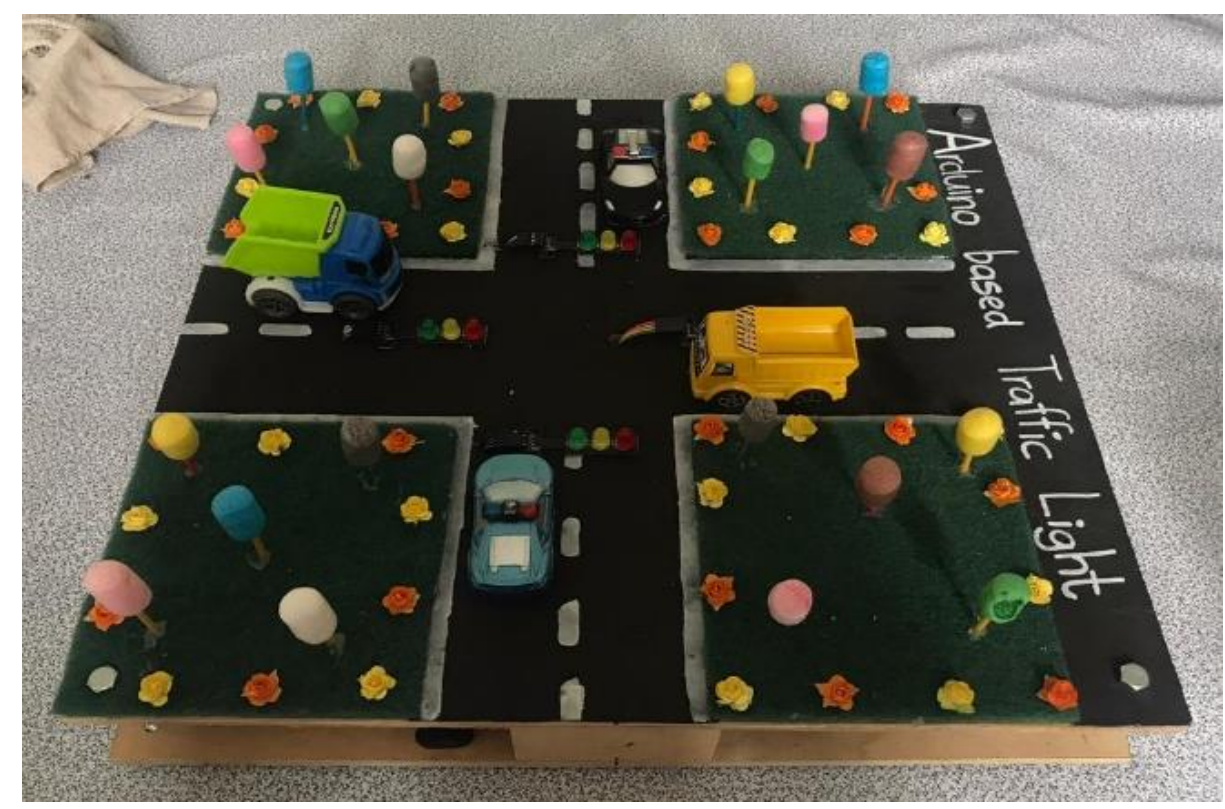

Figure 4: Final Design of the Project 


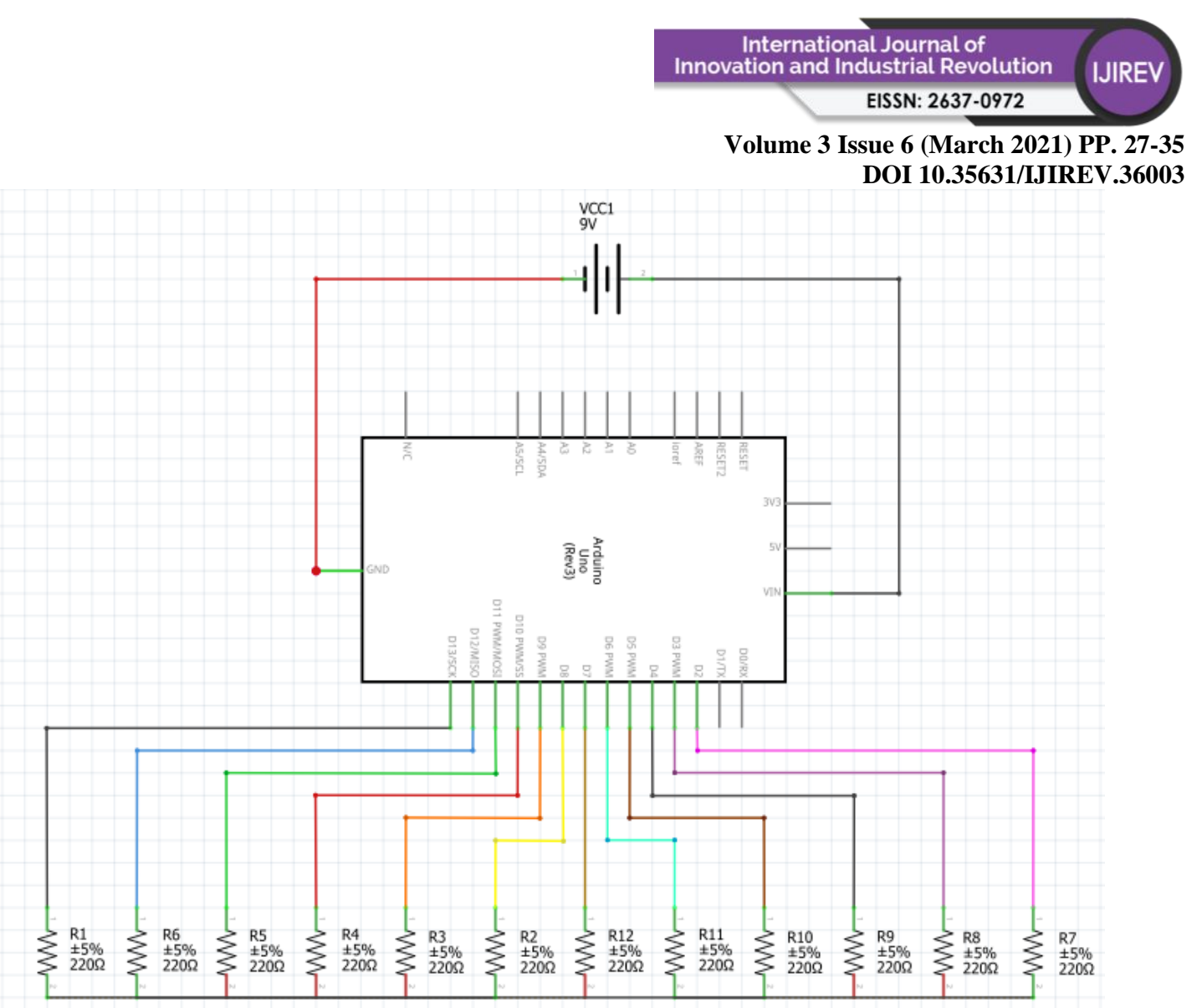

Figure 5: Schematic Diagram for the Main Circuit of the Prototype

\section{Learning Approach}

The goal of this kit is to assist students in understanding and writing simple coding. The medium of the lab sheet, that follows a step-by-step guide that the users may use to refer, configure and program the kit with the expected outcome to further understands in writing the code. This approach has been documented in a sheet that has been meticulously labeled with various explanations to assist the users. The sheet also explains the theory that applies to the kit as well as the operating principles of the components used. Table 3 below illustrated the structure of combining both theory and practice following the structure of the said sheet. The programming exercises performed via this kit as a basic guide in writing the program coding.

Table 3: Stepwise Learning Approach

\begin{tabular}{|c|c|l|}
\hline No. & Steps & \multicolumn{1}{c|}{ Contents } \\
\hline 1 & What to learn? & $\bullet$ Educational kit introduction \\
\hline 2 & What is Arduino? & $\begin{array}{l}\text { - Introduction to Arduino } \\
\text { - The theory of Arduino and its features } \\
\bullet \text { Setting up the kit }\end{array}$ \\
\hline 3 & Learning the program & $\begin{array}{l}\bullet \text { Introduction to programming } \\
\text { - The basic language for the programming }\end{array}$ \\
\hline 4 & Electronic components & - Identifying the components involved \\
\hline 5 & Operation & - Introduction to traffic lights operations \\
\hline 6 & & $\begin{array}{l}\text { - Sample of labeled program bait. } \\
\text { - Scenarios and problems will be given to } \\
\text { help users practice with the expected } \\
\text { outcome. }\end{array}$ \\
\hline
\end{tabular}




\section{Finding and Analysis}

At the start of this project, a short survey was distributed on the subject of the final year project theme for December 2019's session. Based on this short survey, it is cleared that the final year Politeknik Mukah Mechanical Engineering's students failed in understanding and listing the concept of IR 4.0 thus leading to the discovery of their difficulties using Arduino and writing up simple Arduino's program. Figure 5 below shows the result obtained from the short poll.

\section{Preliminary Review Poll}

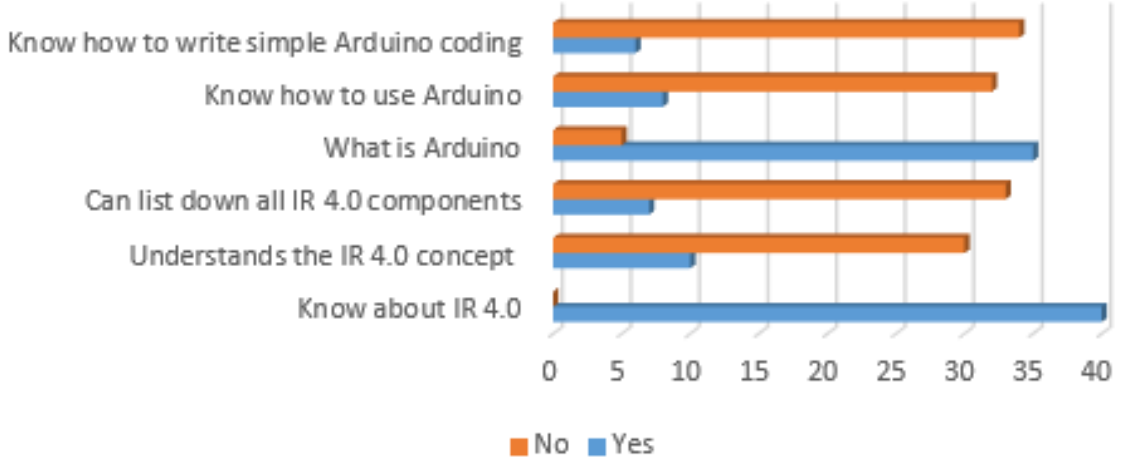

Figure 5: Preliminary Review Poll

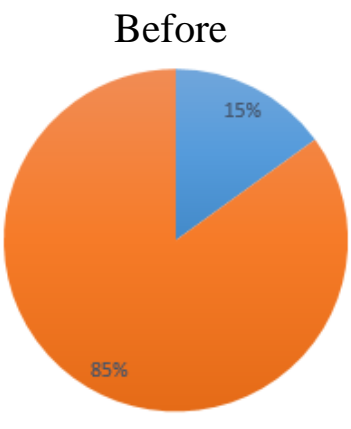

mes $m$ No

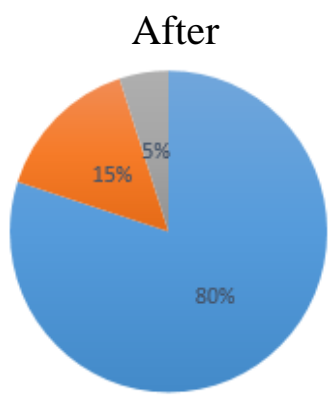

- Yes = Maybe $=$ No

Figure 6: Percentage of Students on Writing Simple Arduino Programming Code Before and After Using the Educational Kit Prototype

Figure 6 above shows that $85 \%$ of the responder, answered they have difficulties in writing simple Arduino programming code. Stating that Arduino was not a part of their curriculum during their studies here in Politeknik Mukah and due to the theme of their FYP which is IR 4.0. The students choose Arduino as the most affordable and accessible IR 4.0 components which fall in the category of automation. With the same targeted responder, $40 \mathrm{FYP}$ students were allowed to test run the prototype and observed. After testing ends, the subjects were then asked the same question on whether they still faced difficulties in writing a simple Arduino coding. As shown in the same Figure 6, below $80 \%$ of the students responded as they can write a simple Arduino programming code after using the prototype while $15 \%$ of them responded they could and the remaining 5\% responded they still required help. 


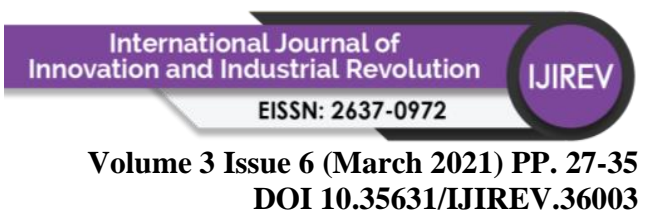

\section{Conclusion}

At the end of this project, it can be concluded that this prototype can be used as an alternative for the lecturers and students to gain basic knowledge in Arduino program code writing. The aim for the prototype has been achieved. It was proven that the final year student of Politeknik Mukah's Mechanical Engineering course that used the prototype has shown an increase of the basic program code writing. Compared to the preliminary survey, the increase of $65 \%$ of users managed to overcome their code writing difficulties. The FYP students were able to confidently in attempting a far more complicated program writing.

\section{References}

Barragán, H. (2004). Wiring: Prototyping Physical Interaction Design. Ivrea: Interaction Design Institute Ivrea.

Cross, N. (2008). Engineering Design Methods: Strategies for Product Design, 4th Edition. Chichester: Wiley.

Gibilisco, S. (2014). Beginner's Guide to Reading Schematics, Third Edition. New York: McGraw-Hill Education.

Idris, R. (2019). Industrial Revolution 4.0: An Overview of Readiness and Potential Economic Effects in Malaysia from Millennial's Perspective. World Scientific News, 274-280.

J.M, H. (2016). Arduino: A Technical Reference. O'Reilly Media, Inc.

Karl T. Ulrich, S. D. (2008). Product Design and Development 4th Edition. New York: McGraw Hill.

Lindsay, D. (2011). Scientific Writing = Thinking in Word. CSIRO Publishing.

Loius, L. (2016). Working Principle of Arduino and Using it as a Tool for Study and Research. International Journal of Control, Automation, Communication and Systems (IJCACS) Vol. 1, No. 2, 21-29.

Luiz A. Junior, O. T. (2013). A Low-Cost and Simple Arduino-Based Educational Robotics Kit. Journals in Science and Technology, Journal of Selected Areas in Robotics and Control (JSRC), December Edition, Volume 3, Issue 12, 1-7.

Margolis, M. (2011). Arduino Cookbook. California: O’Reilly Media, Inc.

MITI. (2018). Industry 4WRD: NATIONAL POLICY ON INDUSTRY 4.0. Kuala Lumpur, Malaysia: Ministry of International Trade and Industry (MITI).

Pugh, S. (1981). Concept Selection: A Method That Works. Hubka, V. (ed.), Review of Design Methodology. Proceedings International Conference on Engineering Design (pp. 497506). Rome: Zurich Heurista.

Rojko, A. (2017). Industry 4.0 Concept: Background and Overview. International Journal of Interactive Mobile Technologies (iJIM) Vol 11, No 5, 77-90.

Schwab, K. (2016). The Fourth Industrial Revolution: what it means, how to respond. Retrieved from World Economic Forum: https://www.weforum.org/agenda/2016/01/the-fourth-industrial-revolution-what-itmeans-and-how-to-respond/

Waguespack, C. (2014). Mastering Autodesk Inventor 2015 and Autodesk Inventor LT 2015: Autodesk Official Press. Indiana: John Wiley \& Sons, Inc.

Zabidi M.I.Z.M., Y. L. (2018). E-Transform: High School Educational Kit for Learning Mathematical Transformation. Proceedings of Innovative Teaching and Learning Research Day 2018. 